\title{
Effects of hydrogen peroxide treatment on the particle size distribution of hydrothermal vent sediments: A case study in Guishan Island, Taiwan
}

\author{
Wei-Ling Ng1, Cheng-Ann Chen ${ }^{*}$, Stephenie Demie ak. Kawi' ${ }^{1}$, Baba Musta² and Tin-Yam Chan ${ }^{3}$ \\ ${ }^{1}$ Borneo Marine Research Institute, Universiti Malaysia Sabah, Jalan UMS, 88400 Kota Kinabalu, Sabah, Malaysia \\ ${ }^{2}$ Faculty of Science and Natural Resources, Universiti Malaysia Sabah, 88400, Kota Kinabalu, Sabah, Malaysia \\ ${ }^{3}$ Institute of Marine Biology and Center of Excellence for the Oceans, National Taiwan Ocean University, Keelung \\ 20224, Taiwan, R.O.C.
}

*Corresponding author: chengann@ums.edu.my

\begin{abstract}
Particle size analysis is able to reveal essential information about processes like production, transportation, sorting, and deposition of a study area. Pre-treatment of sediment by using hydrogen peroxide is recommended for more accuracy of particle size distribution as it removes organic matter which is adsorbed on the grain particle. A shallow water where hydrothermal vents site are located in Guishan Island is selected as the study site in this research. Sediment samples were collected at the depth of $3-5 \mathrm{~cm}$ from the seabed surface by SCUBA diving. Particle size analysis was conducted by dry sieving before and after hydrogen peroxide treatment. Results showed significant differences in very coarse sand $(p<0.05)$ as it decreases significantly in weight after treatment ( $10.62 \%$ of change). The other particle size level of sediment increases slightly in weight and the changes ranged from $1.20 \%$ to $2.60 \%$, showing no significant difference $(500 \mu \mathrm{m}=0.59$; $\mathrm{p}$ value $250 \mu \mathrm{m}=0.67$; $\mathrm{p}$ value $125 \mu \mathrm{m}=0.48$; $\mathrm{p}$ value $63 \mu \mathrm{m}=0.47 ; \mathrm{p}$ value $>63 \mu \mathrm{m}=0.38$ ). Therefore, in order to accurately determine the particle size distribution at hydrothermal vent site, pre-treatment using hydrogen peroxide is recommended to remove organic material because hydrothermal vent is proved to have high organic matter content.
\end{abstract}

Keywords: Sediment, Hydrothermal vent, Taiwan, Hydrogen peroxide

\section{Introduction}

Particle size analysis can be carried out with many methods such as laser grain size analysis with pipette, sieve analysis and electrical sensing (Konert and Vandenberghe, 1997). Each of these techniques defines the size of a particle and also measures different properties of the same material. Analysis of particle size can reveal the texture of the sediment which is essential as it provides information about processes like production, transportation, sorting, and deposition of the study area (Vasskog et al., 2016). However, several studies suggested that pre-treatment of sediment is required to remove organic constituents in the sediment for more accuracy of particle size distribution (Konert and Vandenberghe, 1997; Leifeld and Kögel-Knabner, 2001; Gray et al, 2010; Vasskog et al., 2016).

Pre-treatment of sediment with hydrogen peroxide is not an essential requirement but it is commonly done in case of marine sediment. To determine particle size of marine sediment, pre-treatment of sediment is recommended to remove organic matter $(\mathrm{OM})$ because $\mathrm{OM}$ gets incorporated in marine sediment which then deposits when water is oxygenated (Hedges and Keil, 1995). Pre-treatment with hydrogen peroxide removes $90 \%$ of the organic carbon (OC) and about $80 \%$ of nitrogen component (Leifeld and KögelKnabner, 2001). However, the efficiency of removing organic carbon also depends greatly on the properties of sample.
Several studies have shown that hydrogen peroxide has an effect on measured particle size distribution (Konert and Vandenberghe, 1997; Vasskog et al., 2016). However, most of the studies were conducted on lake sediment (Meyers and Lallier-Verges, 1999; Vasskog et al., 2016), alluvial and marsh sediment (Gray et al., 2010), and land (Leifeld and Kögel-Knabner, 2001; Mikutta et al., 2005), but there is no published data on the sediment from hydrothermal vent. Hydrothermal vent, or underwater volcanoes, are commonly found near volcanically active places (spreading centres or subduction zone of tectonic plates). Chimney-like structure are formed when the hot hydrothermal fluids (over $400^{\circ} \mathrm{C}$ ) solidifies upon cooling. There are two types of vents, 'white smokers' and 'black smokers' where the former vents emit white smoke made up of barium, calcium, and silicon whilst the latter emit black smoke made up of iron sulphide (Konn et al., 2015; NOAA, 2018). Konn et al. (2015) conducted studies at the hydrothermal vents of Mid-Atlantic Ridge and found that the vents produced high amount of hydrogen $\left(\mathrm{H}_{2}\right)$ which then leads to the formation of abiogenic methane $\left(\mathrm{CH}_{4}\right)$. This indicates that hydrothermal vents are high in organic matter. Therefore, pre-treatment of sediment from hydrothermal vent is recommended for particle size analysis to ensure the accuracy of results. 


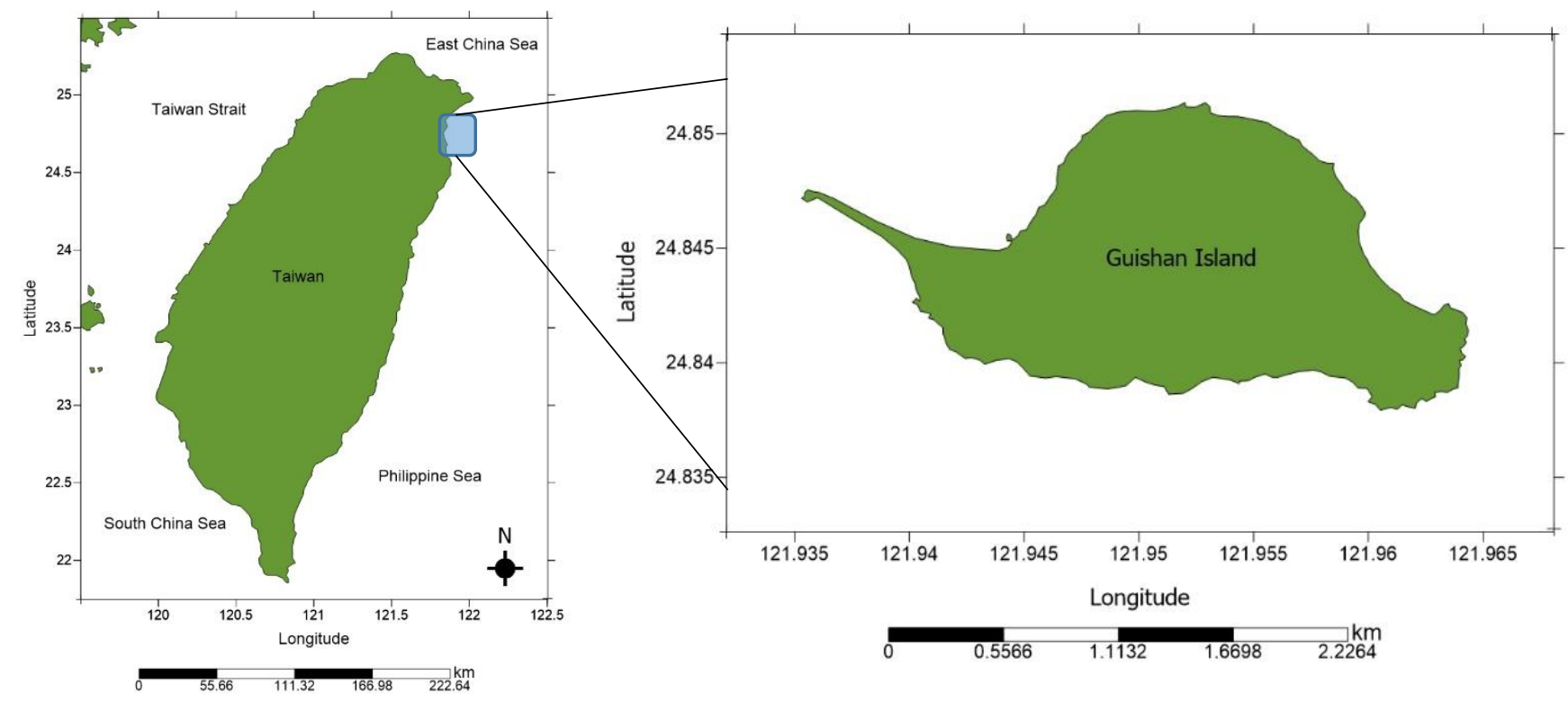

Figure 1. Location of Guishan Island.

Guishan Island, where this study was based, is one of the shallow water vents which provides a unique study ecosystem as compared to deep sea hydrothermal vents (Comita et al., 1984; Bazylinski et al., 1988; Konn et al., 2015;). Results of this study are helpful in bridging the knowledge gaps as well as for future research on shallow water hydrothermal vents. Perhaps, it is for the first time that the hydrogen peroxide treatment was used for hydrothermal vent sediments. The objectives of the study are: (1) to determine the sediment particle size from hydrothermal vent before and after treatment of hydrogen peroxide and (2) to ascertain the percentage of interference caused by organic matter without hydrogen peroxide pretreatment.

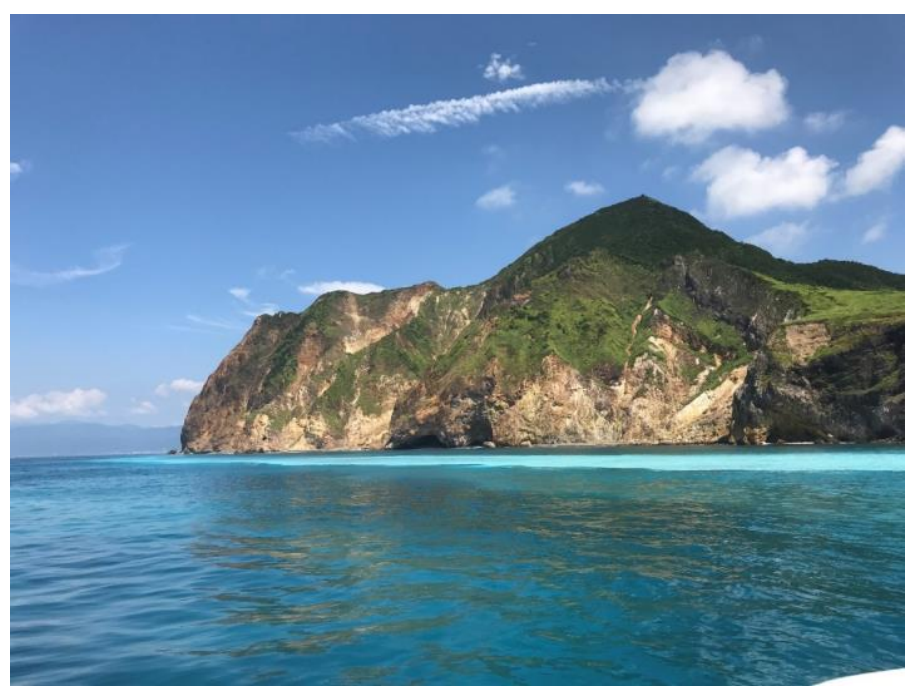

Figure 2. Sampling site at Guishan Island.

\section{Methodology}

Sampling was conducted in June 2018 in the hydrothermal vent area of Guishan Island (Figure 1). The location of the study site was $24^{\circ} 50^{\prime} 06.2^{\prime \prime} \mathrm{N} 121^{\circ} 57^{\prime} 01.6 " \mathrm{E}$ (Figure 2). Three replicates of transects $\mathrm{A}, \mathrm{B}$ and $\mathrm{C}$ were stretched horizontally outwards from one vent mouth (Figure 3), and sediment samples were collected by SCUBA diving. Each transect was $20 \mathrm{~m}$ long while the distance between each station was $5 \mathrm{~m}$. There were 5 stations in each transect. All sediments were collected from approximately $3-5 \mathrm{~cm}$ of seabed surface; subjected to the sediment availability in the area. The length of transect and the distance between stations were set to determine the distance of sulphur disturbance from the vents.

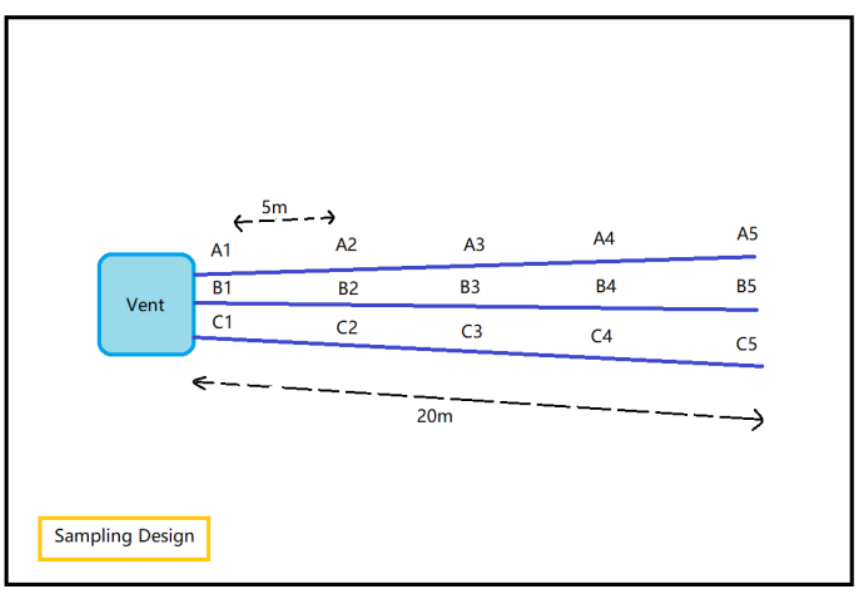

Figure 3. Sampling design along Guishan Island. 


\section{Particle size analysis}

The present experiment was conducted repeatedly using the same subsamples. Sediment samples collected from Guishan Island were first dried under the sun to remove moisture. Then, subsamples of $100 \mathrm{~g}$ were weighed from each collected sample for dry sieving according to the method of Bale \& Kenny (2005). Particles size of the untreated subsamples was determined using a stacked series of sieves $(1 \mathrm{~mm}, 500 \mu \mathrm{m}$, $250 \mu \mathrm{m}, 125 \mu \mathrm{m}, 63 \mu \mathrm{m}$, and a pan to retain particle $<63 \mu \mathrm{m}$ ). Subsequently, the stacked column was transferred to sieve shaker for 10-15 minutes for agitation. Weight of the sediment retained on each of the sieves including the pan (silt and clay fractions) was measured.

Hydrogen peroxide treatment of the subsamples was carried out using $250 \mathrm{ml}$ of $6 \%$ hydrogen peroxide over a period of 12 hours. Filter paper (Whatman 50) in a vacuum filter was used to wash the content. A volume of $25 \mathrm{ml}$ of sodium hexametaphosphate solution $(6.2 \mathrm{~g} / \mathrm{L}$ aqueous $)$ was added with $200-300 \mathrm{ml}$ of distilled water and stirred for 15 minutes, and the contents were allowed to stand undisturbed overnight. Sediments were stirred again for 15 minutes then sieved using $63 \mu \mathrm{m}$ sieve. Sediment with particle size $<63 \mu \mathrm{m}$ were filtered (Whatman Glass Microfiber Filter GF/B) using vacuum filter. Steps of dry sieving method were repeated and weight of the sediment retained on each sieve was recorded. Table 1 shows sediment size class according to the Wentworth (1922).

Table 1. Particle size classes according to the standard scale.

\begin{tabular}{ll}
\hline Size & Size Class \\
\hline$>1 \mathrm{~mm}$ & Very coarse sand \\
$500 \mu \mathrm{m}-1 \mathrm{~mm}$ & Coarse sand \\
$250 \mu \mathrm{m}-500 \mu \mathrm{m}$ & Medium sand \\
$125 \mu \mathrm{m}-250 \mu \mathrm{m}$ & Fine sand \\
$63 \mu \mathrm{m}-125 \mu \mathrm{m}$ & Very fine sand \\
$<63 \mu \mathrm{m}$ & Silt \\
\hline
\end{tabular}

One-way analyses of variance (ANOVA) with post hoc Fisher's Least Significant Difference was performed using SPSS v25 to determine the level of significance among the data of the two experiments for each particle category. The $\mathrm{H}_{0}$ for all the ANOVAs where the significant difference did not occur among the tested groups was rejected. Cluster analysis was carried out using PRIMER 6 subjected to Euclidean Distance resemblance on percentage of particle categories (with $v s$. without pre-treatment) to determine the similarity of all particle groups between the two experiments.

\section{Results}

Results of the one-way ANOVA analyses showed significant differences in very coarse sand $(p<0.05)$. This category of the sand amounted to $67.57 \%$ before the treatment but $56.95 \%$ after the treatment (Figure 4). Particle sizes before treatment for coarse sand, medium sand, fine sand, very fine sand, and silt were $15.43 \%, 6.26 \%, 7.36 \%, 2.5 \%$, and $0.87 \%$, respectively but values of the mean percentage were higher after treatment hydrogen peroxide treatment: coarse sand, 16.98g; medium sand, $7.47 \mathrm{~g}$; fine sand, $9.39 \mathrm{~g}$; very fine sand, 4.56g; and silt, $3.4 \mathrm{~g}$ ). Table 2 summarizes the changes in particle size before and after the treatment with hydrogen peroxide. Drastic decline was recorded in the very coarse sand, with a total of $10 \%$ which gradually increased the percentage of particles of other size categories. Very coarse sand registered the largest difference while for other sediments the change was in the range of $1.20 \%$ to $2.60 \%$. Figure 5 shows group average of the percentage of particle changes before and after pre-treatment with hydrogen peroxide for very coarse sands; their highest percentage in the study area suggested this as a distinct category compared to the other sediments.

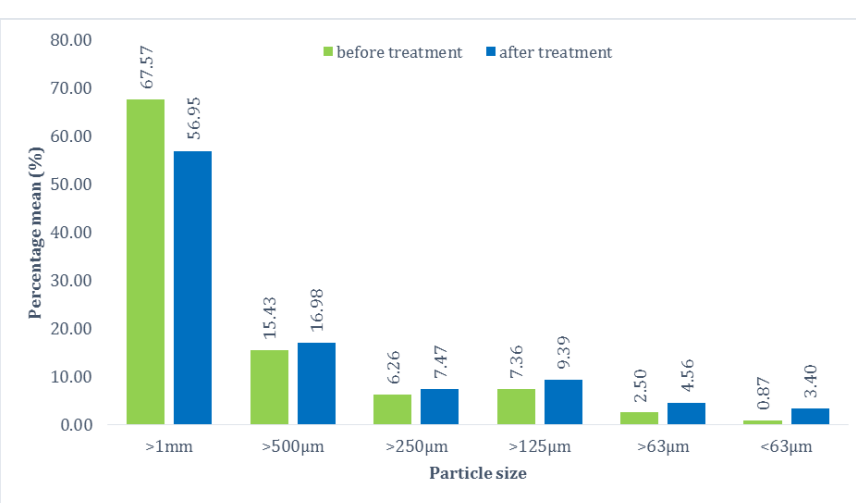

Figure 4. Comparison of particle size before and after hydrogen peroxide treatment (\%).

Table 2. Changes in particle size before and after hydrogen peroxide treatment.

\begin{tabular}{cccccc}
\hline $\begin{array}{c}\text { Particle } \\
\text { Size }\end{array}$ & Before (\%) & After (\%) & $\begin{array}{c}\text { \% of } \\
\text { change }\end{array}$ & Status & Significance \\
\hline $1 \mathrm{~mm}$ & 67.57 & 56.95 & 10.62 & Decreasing0.000 $(<0.05)$ \\
$500 \mu \mathrm{m}$ & 15.42 & 16.98 & 1.55 & Increasing & 0.59 \\
$250 \mu \mathrm{m}$ & 6.261 & 7.46 & 1.21 & Increasing & 0.67 \\
$125 \mu \mathrm{m}$ & 7.36 & 9.39 & 2.03 & Increasing & 0.48 \\
$63 \mu \mathrm{m}$ & 2.50 & 4.56 & 2.06 & Increasing & 0.47 \\
$<63 \mu \mathrm{m}$ & 0.87 & 3.3972 & 2.52 & Increasing & 0.38 \\
\hline
\end{tabular}

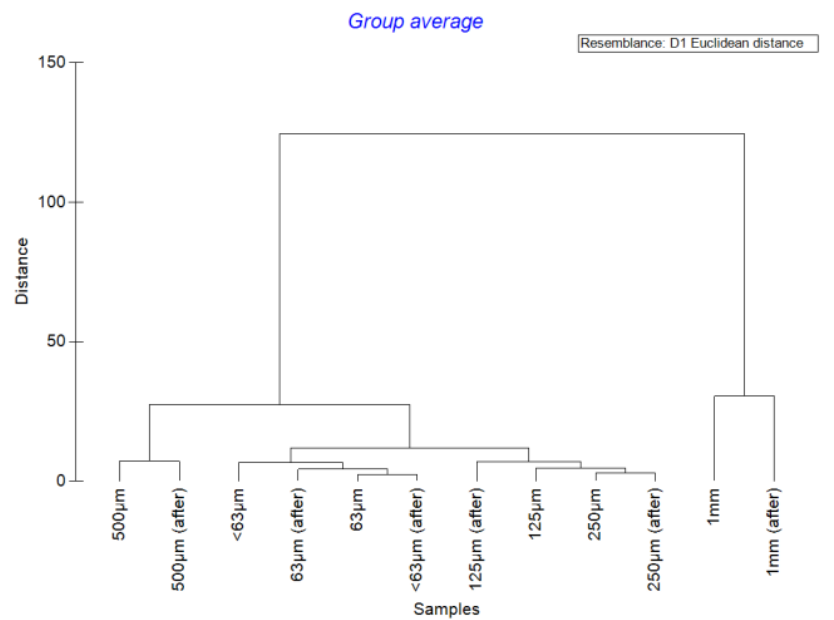

Figure 5. Group average of the percentage of particle changes before and after pre-treatment with hydrogen peroxide. 


\section{Discussion}

Results of the present study showed the highest percentage of change $(10.62 \%)$ of particle size of $1 \mathrm{~mm}$ (very coarse sand), which decreased from $67.57 \%$ to $56.95 \%$ after hydrogen peroxide treatment. Organic molecules tended to adsorb on the surface of finer sediment, and this aggregated structure turned into larger lump of sediment, misleading the results of particle size distribution before treatment (Bale and Kenny, 2005; Vasskog et al., 2016, Zaghden et al., 2017). Results presented in Table 2 where sediment with particle size $1 \mathrm{~mm}$ recorded higher weight before the treatment. It decreased after treatment, probably because of the digested organic matter or deflocculating, thus, shifting to smaller particle size, increasing the weight of the smaller particle size sediments. In addition, sediments from hydrothermal vent were seen to have high organic matter (Konn et al., 2015) and high quantity of hydrocarbon in the $0-10 \mathrm{~cm}$ section from the core sample from Guaymas Basin hydrothermal vent site (Bazylinski et al., 1998). Percentage of changes in particle size $>1 \mathrm{~mm}$ was up to $10 \%$, while other particle size sediment only increased approximately $2 \%$ which does not add up to $10 \%$. Thus, the sediment was definitely being deflocculating but organic matter was also probably lost during the treatment. Removing the organic matter in sediment is crucial to reveal detailed information such as texture of sediment, processes like production, transportation, sorting, and deposition occurring in the study area (Konert and Vandenberghe, 1997; Leifeld and Kögel-Knabner, 2001; Gray et al, 2010; Vasskog et al., 2016). Properties of sediment such as porosity and permeability can also be altered due to the bonding of the organic matter in a marine ecosystem. Keller (1982) and Hamouche and Zentar (2018) concluded that high organic matter in sediment absorbs water and causes clay-size particles to aggregate, resulting in larger sediment size. This justifies the higher weight of large particle size $(1 \mathrm{~mm}$; very coarse sand) before treatment which decreases after the treatment. Other size classes increase in weight because the treatment not only dissolved organic matter in the sediment but also due to break up of organic bonding between silt and clay particle, leading to a shift of sediment from larger particle size class to smaller particle size class.

The precision of the particle size analysis provided information on the distribution of coarser and finer grain which enabled the characterization of the physical properties of sediment. This is important in this current age of technological developments, especially in the field of geotechnical and civil engineering such as the utilization of marine sediment for the construction of roads and strength of cement for various uses (Hamouche and Zentar, 2018). Furthermore, high organic content in sediment is known to cause excessive pore pressure or high porosity, thus affecting the properties of the sediment (Keller, 1982; Hamouche and Zentar, 2018) that aids in determining physical processes such as intensity of upwelling at the study area (Keller, 1982). Particle size analysis can also provide information on the type of species, preferences and adaptability of benthic community inhabiting the sediment that undoubtedly plays an important role in marine food web (Chen et al., 2012). Moreover, the possible contamination of marine ecosystems can be determined through particle size analysis. This is because contaminants or biogenic particulate material adsorbs onto particles in the water column then deposits in sediment (Zaghden et al, 2017). Therefore, pre-treatment to remove organic matter of sediment from hydrothermal vent is recommended for particle size analysis to ensure accuracy of the results.

\section{Conclusion}

The current study indicated the reasons for discrepancy in the sediment characteristics before pre-treatment with an approximate of $2 \%$ for all particles size (coarse sand, medium sand, fine sand, very fine sand, and silt). This can be compared to very coarse sand where it was $10 \%$ due to the bonding of organic matter onto the smaller grain size in the hydrothermal vent area of Guishan Island. Obviously, very coarse sand shows significant differences before and after hydrogen peroxide treatment. In this study, only sediment categorised as the very coarse type decreased in weight after pre-treatment while all the other particle size categories (coarse sand, medium sand, fine sand, very fine sand, and silt) increased in weight after pre-treatment. The highest percentage of change $(10.62 \%)$ in very coarse sand indicates high organic matter in the sediment of hydrothermal vent as organic matter was digested and organic bond was broken during the pre-treatment of sediment. For accurately determining the particle size distribution at hydrothermal vent site it is recommended to perform pre-treatment using hydrogen peroxide to remove organic matter because hydrothermal vent is a rich source of organic substances.

\section{Acknowledgement}

The authors would like to thank Ministry of Education, Taiwan for funding this research. Facilities were provided by National Taiwan Ocean University and Borneo Marine Research Institute, University Malaysia Sabah. Our special thanks to National Taiwan Ocean University for the assistance provided for the samplings.

\section{References}

Bale, A.J. \& Kenny, A.J. (2005). Sediment Analysis and Seabed Characterisation. Methods for The Study of Marine Benthos. Third Edition. 2, 44-86.

Bazylinski, D.A., Farrington, J.W., \& Jannasch, H.W. (1998) Hydrocarbons in Surface Sediments from A Guaymas Basin Hydrothermal Vent Site. Organic Geochemistry 12(6), 547-558.

Chen, C.A., Long, S.M., \& Rosli, N.M. (2012). Spatial Distribution of Tropical Estuarine Nematode Communities in Sarawak, Malaysia (Borneo). The Raffles Bulletin of Zoology 60(1), 173-181.

Comita, P.B., Gagosian, R.B., \& Williams, P.M. (1984). Suspended Particulate Organic Material from Hydrothermal Vent Waters At $21^{\circ} \mathrm{N}$ Nature 307, 450-453.

Gray, A.B., Pasternack, G.B., \& Watson, E.B. (2010). Hydrogen Peroxide Treatment Effects on The Particle Size Distribution of Alluvial Marsh Sediments. The Holocene 20(2), 293-301. 
Volume: 03 (02) | Dec 2019, 52 - 56

Hamouche, F. and Zentar, \& R. (2018). Effects of Organic Matter on Mechanical Properties of Dredged Sediments for Beneficial Use in Road Construction. Environmental Technology.

Hedges, J.I., \& Keil, R.G. (1995). Sedimentary Organic Matter Preservation: An Assessment and Speculative Synthesis. Marine Chemistry $49,81-115$.

Keller, G.H. (1982). Organic Matter and The Geotechnical Properties of Submarine Sediments. Geo-Marine Letters 2, 191-198.

Konert, M. \& Vandenberghe, J. (1997). Comparison of Laser Grain Size Analysis with Pipette and Sieve Analysis: A Solution for The Underestimation of The Clay Fraction. Sedimentology 44, 523-535.

Konn, C. Charlou, J.L., Holm, N.G., \& Mousis, O. (2015). The Production of Methane, Hydrogen, and Organic Compounds in Ultramafic-Hosted Hydrothermal Vents of the Mid-Atlantic Ridge. Astrobiology 15(5), 381399.

Leifeld, J., \& Kögel-Knabner, I. (2001). Organic Carbon and Nitrogen in Fine Soil Fractions After Treatment with Hydrogen Peroxide. Soil Biology and Biochemistry 33, 2155-2158.

Meyers, P.A., \& Lallier-Verges, E. (1999). Lacustrine Sedimentary Organic Matter Records of Late Quaternary Paleoclimates. Journal of Paleolimnology 21, 345-372.

Mikutta, R., Kleber, M., Kaiser, K., \& Jahn, R. (2005). Review: Organic Matter Removal from Soils using Hydrogen Peroxide, Sodium Hypochlorite, and Disodium Peroxodisulfate. Soil Science Society of America Journal 69, 120-135.

NOAA. What is Hydrothermal vent? National Ocean Service website, https://oceanservice.noaa.gov/facts/vents.html

Vasskog, K., Kvisvik, B.C., \& Paasche, Ø. (2016). Effects of Hydrogen Peroxide Treatment on Measurements of Lake Sediment Grain-Size Distribution. Journal of Paleolimnology.

Wentworth, C. K. (1922). A Scale of Grade and Class Terms for Clastic Sediments. Journal of Geology 30(5), 377-392.

Zaghden, H., Tedetti, M., Sayadi, S., Serbaji, M.M., Elleuch, B. \& Saliot, A. 2017. Origin and Distribution of Hydrocarbons and Organic Matter in The Surficial Sediments of The Sfax-Kerkennah Channel (Tunisia, Southern Mediterranean Sea). Marine Pollution Bulletin 117, 414-428. 